\title{
A Study on the Strain and Function of One-Humped Dromedary Foot Pad
}

\author{
Dr. Yaser A. Hadi \\ Mechanical Engineering Technology Department, Yanbu Industrial College, Saudi Arabia
}

\begin{abstract}
The purpose study will discover the evident analysis of one humped dromedary foot. The analysis influences in finding sand of the camel sole in slipper regions that would support in discovery of footpad and foot syndromes. Behaviour of sole pad penetration into sand was predicted on camel's fore and rear feet using computed technique, for the corresponding segments at the same weights and speeds and for their selected distinctiveness. Camel walk's and his ordinary steps and increase speed to travel and cut off roads and deserts with the magnitude of the weights have a direct impact on the camel feet and stretch the pads, which requires the study of the case and shape of these feet-pads, and not to dive into the soft sand to walk through. For analysis, a 3D model was used. This was done using engineering programs draw a rough shape of the feet-pad through which can note the change, by changing the speed with or without bearing weight on his back. The results revealed that, their container sides were disconnected from the ground by footpad and the interdigital notch of the sole pad were appeared with various scales and colors.
\end{abstract}

Keywords: Dromedary, Foot Pad, Interdigital Notch, Strain

\section{Introduction}

This era is the era of scientific prosperity and the era of the emergence of Quran miracles. It has many aspects of the Qur'anic miracle from multiple angles, which man is seen as neutral to the book of Allah. These aspects of the verse, Allah the almighty say in Holy Quran ("Then do they not look at the camels - how they are created?") [1], commanding people to speculate on his creatures that indicate his absolute power and greatness. They are flamboyant while walking. The miracle of Allah in creating camels is marvellous and their structure is unique. They are very strong and powerful. Nevertheless, they can transport very heavy loads.

Quran discourse works to move the human nature. To use of his capabilities of the mind to the acquisition of knowledge and in order to reach the truth. For science to faith leads owner to reflection and contemplation \{"Men who celebrate the praises of Allah, standing, sitting, and lying down on their sides, and contemplate the (wonders of) creation in the heavens and the earth, (With the thought): "Our Lord! Not for naught Hast Thou created (all) this! Glory to Thee! Give us salvation from the penalty of the Fire"), (AlImraan/The Family of Imraan, verse 191). All the findings of scientific studies about camel few of the many, where it still hides many secrets that may unfold as the days.

The verse 17 \{"Do they not look at the Camels, how they are made?"\} Al-Ghaashiya [1]: The Overwhelming, is a model of what could lead to science in all scientific levels, not read anything from the realities of science and its theories, but in what is greater than that where access to those facts key so beautiful guidance from God expert secrets of creation. Although the development of modern transportation, but the role of the camel and its use in economic and social mobility is still important to get to the hard places, especially the desert them. ["And they carry your heavy loads to lands that ye could not (otherwise) reach except with souls distressed: for your Lord is indeed Most Kind, Most Merciful"\} (An-Nahl: The Bee, verse 7). God also said \{"And that we have subjected them to their (use)? of them some do carry them and some they eat"\} (Yaseen, verse 72).

Long-legged camel to raise his body for much of what erupts underneath; they also help him to widening step and agility. And holed foot slippers surrounds strong thick skin featuring pillow broad soft accommodate when camels trampled them above the ground, and then be able to walk up more sand softness, which is difficult for any creature else and makes him worthy of the title "ship of the desert". Camel skin is very thick, the thing that makes him take the fiery heat of the sand. The sweat glands of skin are very few throughout the body and this scarcity help provide water to prevent waste through sweating. His feet consists of fatty tissue provides a lightness and agility in equal efficiently walking off the floor, and slippery, as well as the soft sand

The dromedary walks only on the pads of the two last units, instead of on the sole of the foot, and hence considered as a hoof less digitigrade [2]. The interdigital notch of the dromedary sole pad is a mainly vital section of its locomotor analysis because they tolerate the load of the body mass. Various facets of dromedary have been reviewed, including computed tomography studies, El-Shafey and Sayed-Ahmed 2012 [3] El-Shafey and Kassab 2013 [4]. It has many features, has long legs that end with beautifully created hooves that consist of two toes on each foot, each one of them has a big flat nail. In addition, underneath each toe a wide fleshy skinny 
pad which allows the camel to walk easily on rocky slippery ground or loose sand without sinking with what it carries of heavy weights as well as its huge body. The footpad expands when the camel stomps on the ground and can walk up on soft sand, which is difficult for any other animals.

Dromedary is a fascinating animal and very little study has been reported. It is the exclusive artiodactyls in their systematic engagement of patrolling step and taking an exceptional foot morphology supposed to be an adaptation for this type of movement $[5,6]$. The proposed widespread feet will allow camel to move on uneven and bumpy surfaces whereas the footpad is used to hold onto rock and sharp inclinations. Their feet are secondarily digitigrade, with a splayed-toed foot, loss of hooves count of a wide footpad and loss of the interdigital muscles, permitting the deviation of 3rd and 4th digits [6-7]. Imaging techniques add a major value to evaluation of soft tissue. Computed technique such as SOLIDWORKS, through its high spatial resolution and reasonable variation of tissue divergence is a fastened exceptionally useful technique for visualizing to be proved. Imaging techniques of color scale play a major role in the modern research [8,9]. The main purpose of this research was to clarify the corresponding images of the footpad in "one-humped camel", and in finding data that might be used for evaluation and diagnosis of sole footpad abnormalities.

Penetration processes are highly dissipative and dissipation occurs in small regions. [10] In a groundfiring test of cannonballs, inactive cannonballs are fired onto the particle medium like sand. When a cannonball penetrates into sand, the kinetic energy of the cannonball turns into frictional energy. If many cannonballs are fired into sand, the sand. Particles tend to get hardened due to large frictional heat. Because of the hardening phenomenon, the number of cannonballs that can be fired is limited, and much cost is needed to change the hardened sand. For an efficient management of an impact test site, the temperature distribution in the sand should be known causing hardening phenomenon.

\section{Compositional And Physical Properties}

As the camel toe is one of skin types in its own compositions, as well as it is distinguished by its particular mutations in blood vessels. The sunken layer has sweat glands (tubular, ramified and highly twisted) arranged in egg-shaped clusters [11], as it is about $24 \mathrm{~mm}$ deep of the outer surface of the dermis layer, fig. 1. The difference between the sweat glands on the surface of the camel's body and the sweat glands in the sole is in the way that cells are secreted. Whereas it is tubular and corrosive (apocrine) on the camel's body, it is noncorrosive (merocrine) in the sole. These glands mitigate the temperature of the toe or maintain the temperature stability when the heat of the sand that camels walk on increases.

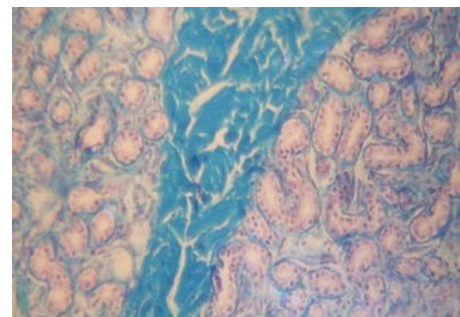

Fig. 1 Sweat glands clusters underneath the dermis layer in the camel sole

The length of the camel soles is about two meters from shoulders, and that is due to its long legs, which keep the body away from the hot ground. The sole has high physiological and mechanical abilities. It is designed in a way not to be instilled in sand and not to cause obstruction in movement. It is also a dielectric material, which protects the camel from lightning strikes that occur in clouds. Furthermore, it is a water pad and used to store water as the toe tissues store water in strand chains. As the stored water increases, the strand wraps more and vice versa. When there is a need for water, the blood absorbs water from the toe and the strand breaks to stay alive for more than three months without water. The camel retains water in the toe in gelatine and crystal pieces that is converted into liquid water, which flows with blood plasma when needed.

The scientific truth in the camel's toe is that it is characterized as a soft elastic tissue like dough and semicircular in shape. The dimensions are $\left(18^{*} 19 \mathrm{~cm}\right)$ in the front legs and $\left(16^{*} 17 \mathrm{~cm}\right)$ in the rear legs. The reason of the difference in dimensions, that the front half is heavier than the back half because of the head and the neck. Unlike human, the toe has a small incision in the front that looks like inseparable two fingers. Therefore, camels are called uncloven hoof as stated in Holy Quran [12]. What is remarkable in the toe is its strength and durability that can carry a huge animal, which may weigh more than $700 \mathrm{~kg}$ as well as more than $250 \mathrm{~kg}$ of load. The sole pad carries this weight and does not explode - despite its softness-, even it expands when it is exposed to the ground and then return to its normal size when rising from the ground, "Glory to Almighty Allah.". Camels walk in the desert carrying loads for long hours on hot sand or rocky slippery ground on which the temperature may reach more than 70 degrees Celsius. The dromedary footpad consists the following: 
1. Thin layer of hard skin, its thickness of about $11 \mathrm{~mm}$.

2. Padded layer for the skin.

3. Flexible tissues.

4. Phalanx bone.

5. Pad of fat based on the Phalanx bone.

\section{Penetration Depth Of Dromedary Foot}

Fig. 2 shows the picture of dromedary foot. Its bones are the densest tissue of the foot and handled it like a wrought calcium, where the sole pads characterized by its round shape with short interdigital cleft (notch).

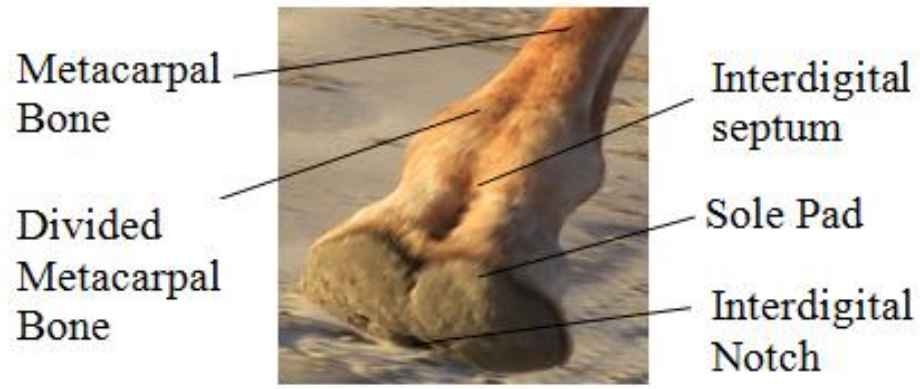

Fig. 2 View of dissected dromedary foot

Since there is no important variances between the right and left sides of the digital bones in the thoracic and pelvic limbs, and to obtain reliable results the material of the sole pad proposed as rubber.

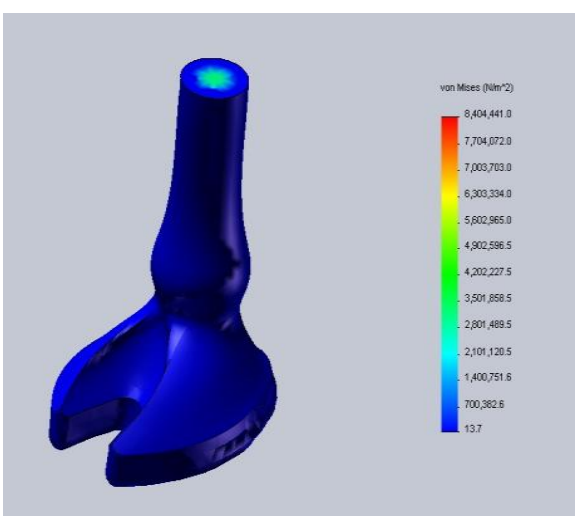

(A)

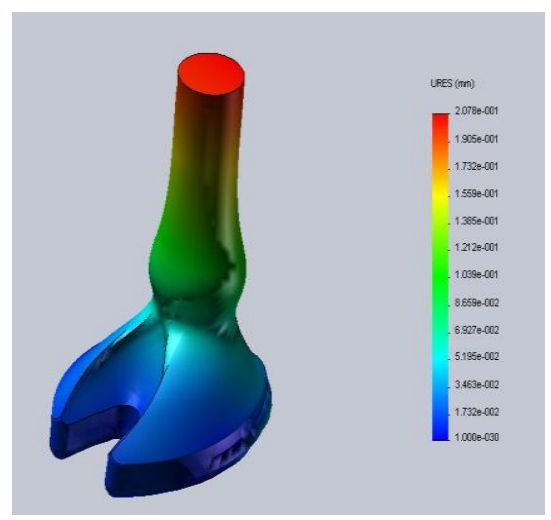

(B)

Fig. 3 Static nodal stress and displacement of dromedary foot

Fig. 3 (A) represents the static nodal Stress of Min: 13.712 N/m2, Max: 8.40444e+006 N/m2, where (B) shows static displacement of Min: $0 \mathrm{~mm}$, and Max: $80.207809 \mathrm{~mm}$. The reaction forces $(\mathrm{N})$ for the three $(\mathrm{X}$, $\mathrm{Y}$, and Z) axes of figure 5 , are $-0.00217844,1488.27,-0.00279227$, respectively.
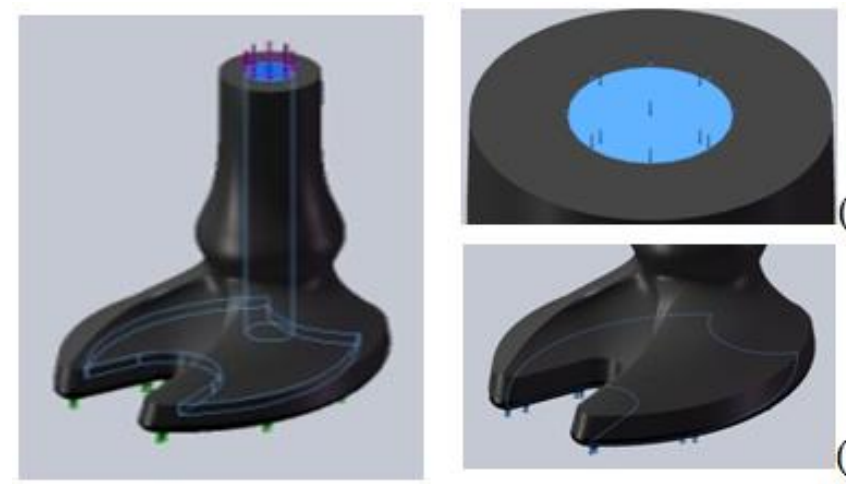

(A)

Fig. 4 Boundary condition of dromedary foot

Fig. 4 shows the linear elastic isotropic of the dromedary foot, (A) apply normal force, and (B) fixed geometry. 


\section{Breadth Of Foot Pad}

The digital bones of the dromedary are predominantly vital components of its locomotors anatomy due to holding the weight of the body mass. Four different computed images figure 5, were obtained and labelled for feet sole pads. The images provided exceptional interpretation and details of explicit analysis when matched to their real actual movements. The properties of the sand were selected from SOLIDWORKS explicit material data. The equivalent strain of figure 5 located at the range of $1.97237 \mathrm{e}-007$ and 0.0089892 . The gravitational acceleration was applied to both the sand and sole pad.



(A)

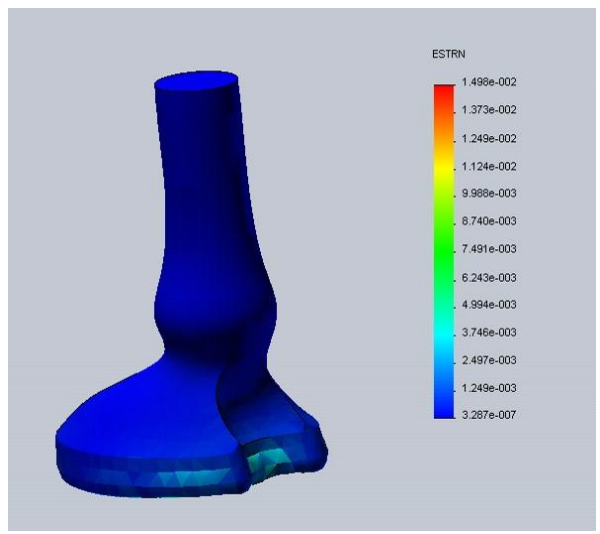

(C)



(B)

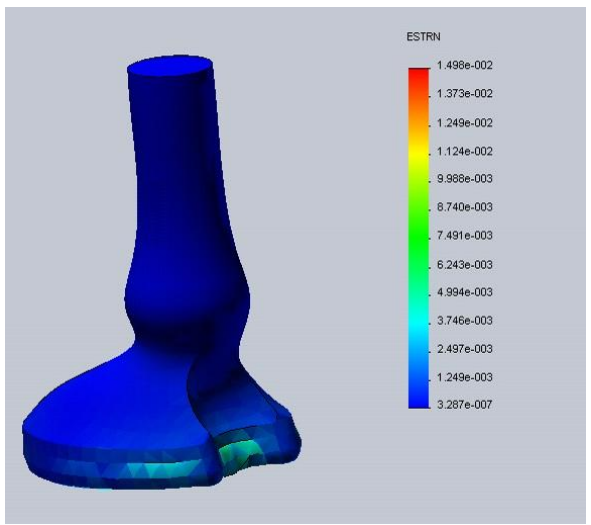

(D)

Fig. 5 Dorsal view of interdigital notch strain

\section{Discussion}

This research would serve as an initial reference for the assessment of imaging of the one-humped dromedary footpad. SOLIDWORKS is a very useful tool and could be covered all aspects of research development process. It is a planar imaging modality, whereas a three-dimensional structure can obscure or confuse important findings. Fig. 3, A, B, C, and D provide images at the level of the individual pad, presenting somewhat curved sole and interdigital notch connection with the ground movement. Noticed the exponential relationship between the interdigital notch and the sole pad, as the weights of the dromedary increase the interdigital notch increases squatting. The sagittal segments with their same images were explained exceptional interpretations of the computerized arrangements of the interdigital notch in camel footpad. The right side feet move forward together, then the feet of the other side, as if it walks on two legs not four. The feet pad might help to tolerate mechanical shock, store and return elastic strain energy, guard alongside local pressure and keep less stress and parade resemblances to the feet of humans [13].

Mostly, Weight dromedary camel ranging $250-700 \mathrm{~kg}$, can carry $150-450 \mathrm{~kg}$ on his back while traveling, and go $144 \mathrm{~km}$ in about 10 hours, with speed $11-16 \mathrm{~m} / \mathrm{s}$. Camel can continue to travel at speeds of up to 16 kilometres per hour continuously for 18 hours at a time, and has been known to travel $186 \mathrm{~km}$ in $12 \mathrm{~h} \mathrm{[14]}$, and any other animal does not achieve this rate. After taking the average values rate of the dromedary weight and walk speed, and using 22 -factorial design, will get the following table with four different results:

Notes from the table 1, there is no a clear and significant change of footpad strain by keeping the speed invariable and the weight factor variable. Simple and the apparent change in light green caused by a change in the speed movement for the camel. 
Table 1. Effect of speed and weight on the squatting of the dromedary footpad

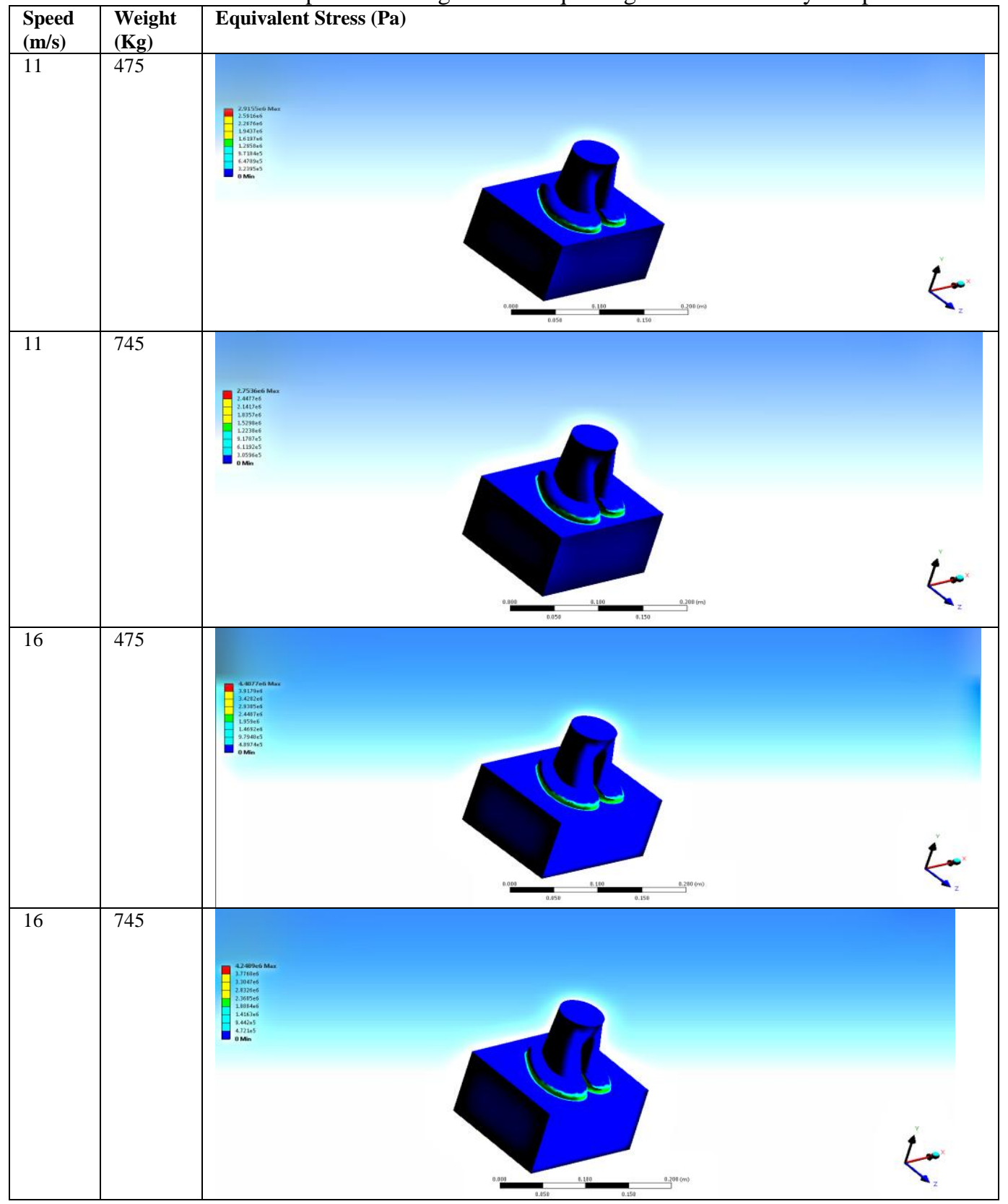

\section{Conclusion}

It is well recognized that, dromedary has exceptional feet particularities. Explicit analysis with proficient imaging modality provides images with greater soft tissue diversity and there was is superimposition of the overlying structures that might be enhanced analysis of footpad irregularities. The dromedary feet have a wide padded interdigital notch that helps it to walk on the soft slippery sand without sinking in. The reason is that the toe is like a footrest or fins but not fingers. Upon checking in walking camels, notes that it puts the entire sole pads on the ground and with the help of interdigital notch carpeted over the ground, this does not exist at any other animal. The dromedary has a unique feature in its gait among quadrupeds. Conclude that, the speed movement is influence factor, which increases the stress on the sole pad, causing spreading on the ground and do not allow washing the dromedary foot in the soft sand.

\section{Acknowledgement}

This research partially supported by Dr. Salah Gasim and Engr. Krunal Patel, colleges and institutes sector at Royal Commission of Yanbu, who provided insight and expertise that greatly assisted the research, although they may agree with all of the interpretations of this paper. 
[2]. Jamal Nourinezhad, Yazdan Mazaheri, and Mohammad Reza Ahi, 2014, Metrical analysis of dromedary digital bones, Japanese Association of Anatomists, 90:113-122.

[3]. El-Shafey A, Sayed-Ahmed A (2012) computed tomography and cross sectional anatomy of the metacarpus and digits of the one humped camel (Camelus dromedaries) and buffalo (Bos bubalis). Int. J Morphol 30:473-482.

[4]. El-Shafey A, Kassab A (2013) computed tomography and cross sectional anatomy of the metatarsus and digits of the one humped camel (Camelus dromedaries) and buffalo (Bos bubalis). Anat Histol Embryol 42:130-137.

[5]. Webb, S.D., 1972. Locomotor evolution in camels. Forma ET Functio, 5: 99-112.

[6]. Janis, C.M., J.M Theodor and B. Biosvert, 2002. Locomotor evaluation in camels revisited: A quantitative analysis of pedal anatomy and the acquisition of the pacing gait. J. Vertebrate Paleontol, 22(1): 110-121.

[7]. Masahiko, M.T., Y. Tetsuya, K. So, B. Rai and H. Yoshihiro, 2002. Regional anatomy of the camel 1l. Comparison of the sole pads of the forelegs and hind legs of the two-humped camel (Camelus Bactrainus). Yamaguchi J. Veterinary Med., 29:11-18.

[8]. Olsen A.K., D. Zeidler, K. Pedersen, M. Sorensen, S.B. Jensen and O.L. Munk, 2007. Imaging S.B. Jensen and O.L. Munk, 2007. Imaging techniques: CT, MRI and PET scanning, pp 387-395. In Swindle MM: Swine in laboratory. Surgery, aesthesia, imaging and experimental techniques. CRC press.

[9]. Olsen, A. K. and M. Winter Dahl, 2009. Imaging techniques in large animals. Scandinavian J. Laboratory Animal Sci., 36(1): 5566.

[10]. Marvin E. Beckman, Werner Goldsmith, “The Mechanics of Penetration of Projectile into Target," International Journal of Engineering Science, vol. 16(1), pp.1-99, 1978.

[11]. Saber, A.S. B. Schenk-Saber and A. Kelany (1988), "The foot pad glands of the dromedary (Camelus dromedaries)", XVII EAVA Congress, Regensburg F.R.G.

[12]. Holy Quran, Surat Al Anaam 146

[13]. Taylor, D.D., D.M. Hood, G.D. Potter, H.A. Hogan and C.M. honnas, (2005) Evaluation of displacement of the digital cushion in response to vertical loading in equine forelimbs, American J. Veterinary Res., 66: 623-629.

[14]. Hildebrand M (1995) Analysis of vertebrate structure, 4th edn. John, Wiley \& Sons, New York 